\title{
THEORETICAL IMPLICATIONS ON VISUAL (COLOR) REPRESENTATION AND CYTOCHROME OXIDASE BLOBS
}

\author{
István Bókkon* and Ram L.P. Vimal \\ Vision Research Institute, Lowell, MA, USA
}

\begin{abstract}
The rich concentration of mitochondrial cytochrome oxidase (CO) blobs in the V1 (striate) primate visual cortex has never been explained. Although the distribution of CO blobs provided a persuasive example of columnar structure in the V1, there are contradictions about the existence of hypercolumns. Since photoreceptors and other retinal cells process and convey basically external visible photonic signals, it suggests that one of the most important tasks of early visual areas is to represent these external visible color photonic signals during visual perception. This representation may occur essentially in CO-rich blobs of the V1. Here we suggest that the representation of external visible photon signals (i.e. visual representation) can be the most energetic allocation process in the brain, which is reasonably performed by the highest density neuronal V1 areas and mitochondrial-rich cytochrome oxidases. It is also raised that the functional unit for phosphene induction can be linked to small clusters of $\mathrm{CO}$-rich blobs in V1. We present some implications about distinction between the physics of visible photons/ light and its subjective experiences. We also discuss that amodal and modal visual completions are possible due to the visual perception induced visualization when the brain tries to interpret the unseen parts of objects or represent features of perceived objects that are not actually visible. It is raised that continuously produced intrinsic bioluminescent photons from retinal lipid peroxidation may have functional role in initial development of retinogeniculate pathways as well as initial appearance topographic organizations of V1 before birth. Finally, the metaphysical framew ork is the extended version of dual-aspect monism (DAMv) that has the least number of problems compared to all other frameworks and hence it is better than the materialism that is currently dominant in science.
\end{abstract}

Key words: Color representation; Visible electromagnetic photons; Amodal and modal visual completions; COrich blobs in V1; Phosphenes; Metaphysics; Materialism; Dual-aspect monism; Visual channels

\section{INTRODUCTION}

The attributes of visible electromagnetic photons, such as wavelength and intensity, are physics, but both exogenous (stimulus/ light dependent) and/ or endogenous (such as phosphenes) colors are subjective experiences related to its attributes hue, saturation, and brightness (Vimal, Pokorny, \& Smith, 1987). When we talk about our visual perception, in reality, we talk about the perception/detection of external electromagnetic visible photons. Although external visible photon signals that are conveyed to V1 can be modulated by other

*Correspondence to: Istvan Bokkon: bokkoni@yahoo.com; url: http://bokkon-brain-imagery.5mp.eu Received January 17, 2013; accepted February5, 2013; Act Nerv Super (Praha) 55(1-2), 15-37. 
sensory modalities during multisensory integration (Calvert, Spence, \& Stein, 2004), it is hardly questionable that photoreceptors and other retinal cells process and convey principally external visible photonic information to Lateral geniculate nucleus (LGN) and then to V1 (primary visual cortex) and other visual areas. It suggests that one of the most important tasks of early V1 area is to represent these detected external photonic signals. Although vision science makes difference between achromatic and chromatic vision, however, both are subjective color experiences produced by mixed visible (color) photon signals in the human eye ranging from about 400 to $700 \mathrm{~nm}$.

Explicitly, in the following sections, we point out that the representation of external visible photon signals (i.e. visual representation) might be one the most energetic allocation processes in the brain, which is reasonably performed by highest density neuronal V1 areas with mitochondrial-rich cytochrome oxidase (CO) areas, which send signals to visual $\mathrm{V} 4 / \mathrm{V} 8 / \mathrm{VO}$ color-related-neural-netw ork. It is also raised that small clusters (3-4 blobs/ $\mathrm{mm}^{2}$ ) of $\mathrm{CO}$ blobs might work as functional units for conscious phosphene perception. In addition, we present some implications about distinction between the physics of visible photons/ light and its subjective experiences since the latter is the mental aspect of color-related-neuralnetw ork-state; its inseparable physical aspect is the V4/ V8/ VO color-related-neural-network and its activities. We also argue that amodal and modal visual completions are possible due to the visual perception induced visual imagery when higher level regions in the brain tries to interpret the unseen parts of objects or represent features of perceived objects that are not actually visible. Then, it is raised that retinal bioluminescent biophotons originated from natural retinal lipid peroxidation might have important role in the development structural organization of visual system before birth. Since we try to elucidate subject experiences related to color, we must clearly disclose our metaphysics. So, finally, the metaphysical framework is the extended version of dual-aspect monism that has the least number of problems. This is called the DAMv framework: the Dual-Aspect Monism with dual-mode and varying degrees of the dominance of aspects depending on the levels of entities, where each entity has inseparable mental and physical aspects (Vimal, 2008, 2010a, 2012; Bruzzo \& Vimal, 2007). This is better than the dominant view, materialism, in science.

\section{HYPERCOLUMN IDEA}

The cortical column notion as a functional unit for monkey somatosensory cortex was first suggested by Mountcastle and co-workers (Mountcastle, 1957; Powell \& Mountcastle, 1959). Soon after ocular dominance column (eye-selective cells) concept was proposed by Hubel and Wiesel (1962) based on recordings from cells in primary visual cortex of anesthetized cats and monkeys (Hubel \& Wiesel, 1962, 1974, 1977). Hubel and Wiesel also proposed that the columns can be assembled into larger units (i.e. hypercolumns constructed by adjacent ocular dominance columns) that include representation of all functions (all orientations and both eyes) within each area of retinotopic space (Hubel \& Wiesel, 1974, 1977). The proposed width of a hypercolumn is $1-2 \mathrm{~mm}$.

A hypercolumn contains a cluster of neurons that respond to the same retinal location, but with different orientation preferences (Horton \& Adams, 2005; Lu \& Roe, 2008). That is, hypercolumns contains three subsystems as ocular-dominance columns, iso-orientation domains, and blobs. The ocular-dominance column is the segregation of inputs from the right and the left eye. These segregated inputs form the ocular-dominance columns, which run almost parallel to one another in slabs. In the iso-orientation domains (or orientationpreference bands), each domain containing cells respond best to a given stimulus orientation. The same hypercolumn also includes the representation of all orientations. The third subsystem includes neurons that are selective for other attributes of the visual stimulus, such as color and spatial frequency. Thus, a hypercolumn contains the representations of all attributes of a stimulus within each area of retinotopic space (receptive field). These neuronal cells are placed in the mitochond rial cytochrome oxidase-rich blobs. 
Although hypercolumn idea suggested by Hubel and Wiesel can be an attractive notion, to date, there are disagreements about the existence of hypercolumns. The visual cortex (like other parts of the cortex) is a continuous sheet and we cannot find a structure that corresponds to the borders between the hypercolumns. Hubel mentions in his Nobel Prize Lecture that the hypercolumns borders are arbitrary, but it didn't seem to worry him. In a recent review by Lund et al. (2003) states that there is no fixed boundary to such hypercolumns as there is a continuous change in property and mean visual field position across the cortex.

In addition, as per (Horton \& Adams, 2005), "Although the column has been offered as the fundamental unit of the cortex, it has not earned this lofty designation. After half a century, it is still unclear what precisely is meant by the term. It does not correspond to any single structure within the cortex. It has been impossible to find a canonical microcircuit that corresponds to the cortical column".

\section{MITOCHONDRIAL CYTOCHROME OXID ASE-RICH BLOBS AND COLOR REPRESENTATION}

In primates, the major pathway serving visual perception runs from the retina via the lateral geniculate nucleus (LGN) to V1, V2, to extra striate areas and distribution to higher cortical regions. From V1, most signals are conveyed to the V2 area before distribution to higher cortical areas.

During visual perception and imagery, the high activity of cytochrome oxidase (CO) is associated with high mitochondrial activity. $\mathrm{CO}$ is the last enzyme in the mitochondrial electron transport chain. The strict coupling between neuronal activity and oxidative energy metabolism is the basis for the use of $\mathrm{CO}$ as an endogenous metabolic marker for neurons (Wong-Riley, 1989). Because CO staining intensity correlates with neuronal functional activity, when we talk about $\mathrm{CO}$ activity we also talk about mitochondrial activity. Namely, $\mathrm{CO}$ activity can have direct link with mitochondrial activity, distributions, and processes (as in neuronal activity) (Bókkon \& Vimal, 2010).

Although the distribution of mitochondrial CO provided a persuasive example of columnar structure in the V1, there are contradictions about the existence of hypercolumns. In addition, a nonlinear distribution of mitochondrial-rich CO blobs, with increased enzyme activity, can be identified in the V1. These blobs can also be revealed by diverse labeling techniques such as increased expression of N-methyl-D-aspartate (NMDA) or $\square$-amino-5hydroxy-3-methyl-4-isoxazole propionic acid (AMPA) receptors, and increased activity glutamate or ATPase, among others (Carder \& Hendry, 1994; Carder, 1997; Wong-Riley, Anderson, Liebl, \& Huang, 1998). Besides, CO blobs appear to be common to all primates (Preuss \& Kaas, 1996). In addition, blobs and interblob are found not only in trichromatic or dichromatic primates but also in nocturnal primates with single functional type of cone within the retina (Wikler \& Rakic, 1990). The functional CO blobs in the supragranular layers extend to layer 6, with the exception of layer 4C (Takahata, Higo, Kaas, \& Yamamori, 2009). Neurons in the V1 blobs have low orientation selectivity but respond to color and have higher firing rates compared to surrounding regions (interblobs) ( $\mathrm{Lu} \&$ Roe, 2008; Economides, Sincich, Adams, \& Horton, 2011).

In $\mathrm{V} 1$, layers 2 and 3 are composed of $\mathrm{CO}$-dense blobs and surrounding regions (interblobs) (Xiao \& Felleman, 2004). V2 is composed of alternating thin and thick CO-rich stripes and the pale interstripe regions between them. According to Sincich et al. (2007), different CO compartments in V1 and V2 are connected in parallel and the projection from V1 CO blobs to V2 CO thin stripes is responsible for color. In addition, V1 and V2 can represent all the principal submodalities of vision such as color, form, motion, and depth (Bartels \& Zeki, 1998).

In the latest experiments by Economides, Sincich, Adams, and Horton, published in Nature Neuroscience (2011), confirmed previously presented notion by Sincich and Horton 
(2005) that the visual attributes of color, form, and motion are not really segregated in V1. According to Economides et al. (2011), V1 contains local cluster of neurons jointly sensitive to orientation and color, perhaps corresponding to cytochrome oxidase blobs. Economides et al. (2011) also mention: "The abundant concentration of cytochrome oxidase in patches or blobs of primate striate cortex has never been explained".

It is lesser-known that the highest density of neurons in neocortex (number of neurons per degree of visual angle) (Rockel, Hoirns, \& Pow ell, 1980; O'Kusky \& Colonnier, 1982) devoted to representing the visual field are found in V1. However, it is hardly accidental that the highest mitochondrial (energetic) activity can be achieved in V1 with mitochondrial CO-rich regions in the brain. Namely, V1 has the highest energy allocation for the visual representation and imagery in the brain, and mitochondrial-rich $\mathrm{CO}$ blobs may represent monocular sites of color processing.

All things that exist in the nature and universe have (dynamic) form (Pereira, 2012). If the (dynamic) form is the quintessence of our world it may support that visual information via reflected visible photons $(400-700 \mathrm{~nm}$ ) from objects/ forms might play the key role in visual perception/representation and imagery. Edwald Hering (a German physiologist (1834-1918) who proposed opponent color theory in 1892) noted in the last century that colors are always spatial. "Our visual world consists solely of differently formed colors [...] seen objects, are nothing other than colors of different kinds and forms" (Hering, 1874).

\section{V1 MAY GUARANTEE THE FINEST AND DETAILED VISUAL REPRESENTATION}

During critical period, both visual stimulation and intact visual regions are necessary for normal development of visual functions and imagery. Although there are contradictions about if mental images and perceived stimuli are represented similarly as well as if V1 is activated during visual imagery, recent experiments support that V1 can be activated during these states in healthy subjects (Chen et al., 1998; Borst \& Kosslyn, 2008; Klein et al., 2004; Cichy, Heinzle, \& Haynes, 2012).

Our presented notions in this paper are related to intact V1 of healthy persons and not to the exceptional subjects with diverse V1 damages, lesions, and malfunctions. Nevertheless, in exceptional V1 cases (damages, lesions), for example, as it was revealed in blindsight phenomenon, there are further possible mechanisms bypassing or helping V1 such as compensation, neural reorganization, preserved "islands" in V1 (geniculostriate visual pathway), projections to the superior colliculus and pulvinar that can provide indirect visual input to the extrastriate areas (retinotectal visual pathway) (Fendrich, Wessinger, \& Gazzaniga, 1992; Ptito \& Leh, 2007), and at present still unknown V1 bypassing visual netw orks. Recently, Boyer et al. (2005) demonstrated that TMS ind uces blind sight in a normal population via an alternate geniculoextrastriate visual pathway that bypasses V1, which can process orientation and color without conscious aw areness.

According to Ganis et al. (2003), "Many sorts of deficits in imagery follow brain damage, but the relation between the site of damage and the type of deficit is not simple or straightforward. The dissociations in performance after brain damage provide hints regarding the processing system underlying imagery, but difficulties in interpretation urge caution in mapping these findings to theoretic models. Neuroimaging techniques, such as PET and fMRI, open a window into the working brain and offer valuable information not easily accessible through the study of patients, who, as noted, may have deficits beyond those observable and may rely on compensation and neural reorganization ".

Lately, Ffytche and Zeki (2012) reported visual awareness in blind fields of three patients with hemianopic field defects. Authors concluded that "the primary visual cortex or backprojections to it are not necessary for visual aw areness", however, they also acknowledged that the blind field experiences of all three subjects were degraded and crude.

If V1 striate cortex can be totally damaged, the processes that would take place there would then take place in the next available V2 visual area. The V2 areas are also well 
retinotopically organized (Cavusoglu, Bartels, Yesilyurt, \& Uludağ, 2012) and preserve the local spatial geometry of the retina (similarly to V1), so patterns of activation in V2 can depict shape (Kosslyn, 1994). There are numerous further visual areas beyond V1 and V2 in what is known as the prestriate cortex, and they have larger receptive fields and cruder topographic organizations. V1 and V2 have comparable surface areas in the brain (Sincich, Jocson, \& Horton, 2007). A map of V2 approximates a mirror image of the V1 (Zeki, 1977). V1 sends most of its cortical output to $\mathrm{V} 2$ and in return receives a strong feedback projection. There are approximately 11,000 feedback neurons in V2 and 14,000 feedforward neurons in V1 (Rockland, 1997). There are especially rapid feed forward and feedback processes between V1 and V2 with conduction velocities around $3.5 \mathrm{~m} / \mathrm{s}$ (Girard, Hupé, \& Bullier, 2001).

According to Sincich and Horton's (2005), “... along with physiological and imaging studies, now make it likely that the visual attributes of color, form, and motion are not neatly segregated by V1 into different stripe compartments in V2. Instead, there are just two main streams, originating from cytochrome oxidase patches and interpatches, that project to V2". It suggests that V2 could represent the principal submodalities of vision such as colour, form, motion and depth. Thus, when V1 can be damaged, V2 may be available to take up V1 roles and produce similar effective visual imagery than V1 should do.

According to latest transcranial magnetic stimulation (TMS) experiments (SalminenVaparanta et al., 2012) human visual awareness cannot be generated without an intact V2. It may support our above mentioned notion that when striate cortex is damaged, V2 may be able to take up V1 roles and produce similar effective visual imagery than V1 should do.

It is also possible that intact V1 may guarantee the finest visual perception and visual imagery, but it is difficult to observe due to the subjective reports of visual experiments and to the significant individual structural variability between normal visual systems of subjects. For example, the mean V1 surface area is $2643 \mathrm{~mm}^{2}$ in human, but the surface range is between 1986-3477 $\mathrm{mm}^{2}$ (Adams, Sincich, \& Horton, 2007). Is it possible that the size of V1 (i.e. the number and size of functional cells in V1) area can have some influence on the visual perception and imagination?

According to Cattaneo, Bona, and Silvanto (2012), it is possible that fine details of imagery for which the small receptive fields of V1 are suited requires the primary visual cortex, although when fine details are not necessary, extrastriate regions are enough for imagery. It is a simple but important question, would size of mitochondria population be correlated with reports of phosphenes and imagery and vividness and individual differences in these phenomena? This would be an important experiment to do in the future.

Energetic processes can have essential role of V1 representation mechanisms. Recent experiments suggest (Basole, White, \& Fitzpatrick, 2003; Basole, Kreft-Kerekes, White, \& Fitzpatrick, 2006) that population activity ((i.e. combinations of different stimulus features such as orientation, direction, spatial frequency) in V1 can be better revealed by a single map of spatiotemporal energy rather than multiple maps of different stimulus features. Recently, we pointed out that spatiotemporal mitochondrial networks and processes can also reflect represented information within neurons during sensory experiences (Bókkon \& Vimal, 2010). Namely, while the brain processes information from different perceptions, the energetic mechanisms (dynamic mitochondria networks and processes activated neurons) have to reflect the perceived information processes because the energy demand of neuronal electrical activity is realized fundamentally by mitochondrial processes. Since sensory information processes are directly linked to mitochondrial energetic processes, it means that information that comes from the different perceptions have to be represented not only by structural processes (such as neural networks) and neuronal electrical activity, but also by spatiotemporal energetic processes of mitochondrial networks within neurons. 


\section{CLUSTERS OF CO-RICH BLOBS AS POSSIBLE FUNCTIONAL UNITS FOR CONSCIOUS PHOSPHEN E PERCEPTION}

Phosphene light perceptions can be produced in the visual hemifield contra-lateral to the stimulated cortical hemisphere and reflect the retinotopic organization of the visual cortex (Brindley \& Lewin, 1968). TMS induced phosphenes can be perceived regardless of whether subjects' eyes are opened or closed. In addition, phosphenes are only perceived by blind patients that have prior visual experience, suggesting that early visual stimulus is essential to maintain any level of residual visual function (Merabet, Theoret, \& Pascual-Leone, 2003). Visual imagery can lower phosphene threshold (PT) (Sparing et al., 2002) suggesting that visual imagery and intrinsic phosphene perception can be in direct functional relationship.

The characteristics of phosphenes are related to the function and receptive field organization of the stimulated neurons. Phosphenes induced in V1, V2, and V3 visual areas usually are stationary small blob-like forms (wedges, crescents, ellipses) (Kammer, 1999). Induced phosphenes in V4 and V5/ MT+ visual regions usually are larger and present a ruder retinotopic structure, and even adopt qualities such as color, motion or texture (Marg \& Rudiak, 1994; Cow ey \& Walsh, 2000).

The CO blobs form nonlinear repeating functional units in V1. According to Tehovnik and Slocum, (2007), "The functional unit for phosphene induction in V1 is most likely the hypercolumn, which is about $1 \times 0.7 \mathrm{~mm}$ of tissue composed of layers spanning some $2 \mathrm{~mm}$ of tissue from the surface of cortex."

The sizes of CO blobs in monkeys are about $514 \mu \mathrm{m}$ in the neonate enucleated and $560 \mu \mathrm{m}$ in normal animals (Kuljis \& Rakic, 1990; Kennedy, Dehay, \& Horsburgh, 1990). Kuljis and Rakic (1990) found that the center-to-center spacing of blobs is $590 \mu \mathrm{m}$ in normal and $598 \mu \mathrm{m}$ in strabismic macaques. In addition, the mean density of blobs was $3.67 \mathrm{blobs} / \mathrm{mm}^{2}$ in normal and 3.45 blobs $/ \mathrm{mm}^{2}$ in strabismic macaques. Besides, CO blobs can develop in the absence of external visual cues from photoreceptors, and the $\mathrm{CO}$ layout of the visual cortex is not modifiable by visual experiences (Kuljis \& Rakic, 1990).

If we compare Tehovnik and Slocum suggestion that the functional unit for phosphene induction is about 1 x $0.7 \mathrm{~mm}$ of tissue with (Kennedy, Dehay, \& Horsburgh, 1990; Kuljis \& Rakic, 1990) experimental results that the size of blobs $514-560 \mu \mathrm{m}$ or $590-598 \mu \mathrm{m}$ in animals, it may suggest that is more reasonable if the functional unit for phosphene induction can be linked to small clusters $\left(3-4\right.$ blobs $\left./ \mathrm{mm}^{2}\right)$ of CO blobs and not definitely to the doubtful and unproved hypercolumns structure.

One may argue that why conscious phosphene perception should be linked to small clusters of CO blobs, because phosphenes can be elicited not only in CO-rich V1 area but also in $\mathrm{V} 2, \mathrm{~V} 3, \mathrm{~V} 4, \mathrm{~V} 5 / \mathrm{MT}+$, intraparietal sulcus (IPS) regions among them .

First, the existence of hypercolumns is doubtful while repeating nonlinear units CO blobs in V1 has been presented by many experiments (Lu \& Roe, 2008, Nakagama \& Tanaka, 2004; Murphy et al, 1998). Second, recent experiments (Fried et al., 2011; Taylor, Walsh, \& Eimer, 2010) suggest that all phosphenes (that can be induced in various regions (such as V2, V3 V4 or V5/MT+, IPS among others) are due to the induced activity of local circuits (local processes contributing to phosphene generation are independent) but feed-forward visual input from excited local circuits to $\mathrm{V} 1$ areas are necessary to phosphene awareness. In addition, since we can interpret the form, color and movement of induced phosphenes, it suggests that not only feed-forward visual input from excited local circuits to V1 are necessary to phosphene awareness but also feed back signals from higher level association areas. Since, as was mentioned, V1 has the highest energy allocation for the visual representation and imagery; it suggests that V1 mitochondrial CO-rich blobs can have especially high role in the energy allocation for the visual representation and imagery.

According to Taylor, Walsh and Eimer (2010), „While the "early” hypothesis suggests that phosphene related potentials after occipital TMS are functionally analogous to motor-evoked potentials following M1 (primary motor cortex) TMS, the "late" hypothesis claims that conscious phosphene perception and its associated phosphene-related potentials are similar 
to the conscious perception of external visual stimuli and its electrophysiological correlates". It suggests that the processing of phosphene perception is very similar to model of the reverse hierarchy vision (Ahissar \& Hochstein, 1997; Hochstein \& Ahissar, 2002).

According to reverse hierarchy hypothesis (Hochstein \& Ahissar, 2002), ...,our initial conscious percept-vision at a glance-matches a high-level, generalized, categorical scene interpretation, identifying "forest before trees." For later vision with scrutiny, reverse hierarchy routines focus attention to specific, active, low-level units, incorporating into conscious perception detailed information available there. Reverse Hierarchy Theory dissociates between early explicit perception and implicit low-level vision, explaining a variety of phenomena". However, this hypothesis can support that visual apperception has the highest energy allocation as we also elucidated in our previously paper (Bókkon \& Vimal, 2010). This extra energy allocation of explicit perception might serve the detailed (holistic (Hochstein et al., 2004) representation of detected visual information in V1 (determines whether that information reaches aw areness (Silvanto, Cowey, Lavie, \& Walsh, 2005).

One of the most important questions in neuroscience is "The Binding Problem". Namely, how encoded items can be combined for coherent perception, decision, and action by distinct brain regions. During object perception, separated visual features must be correctly integrated. According to feature integration assumption (Treisman, 1996), visual stimulation activates feature detectors in striate and extrastriate regions that link automatically to the object nodes in the temporal lobe. Latest studies support that reentrant processing between higher areas and early (V1) visual cortex is critical factor for visual binding and necessary for conscious (and unconscious) visual perception (Koivisto, Mäntylä, \& Silvanto, 2010; Koivisto \& Silvanto, 2012). It may also support the notion that early (V1) visual cortex is critical for conscious visual perception as well as for conscious phosphene perception.

\section{PSYCHOPHYSICS AND NEUROPHYSIOLOGY OF COLOR VISION}

Trichomats have 3 psychophysical visual channels (Kaiser \& Boynton, 1996): Luminance/ Achromatic channel, Red-Green color channel, and Yellow-Blue color channel. Achromatic and chromatic perceptions and representations are processed by the luminance/ achromatic channel and the two chromatic channels (Red-Green color channel, and Yellow-Blue color channel), respectively. Each has a number of tuned mechanisms in orientation (Vimal, 1997), spatial frequency (Vimal, 1998a, 1998b, 2002b), temporal frequency (Metha \& Mullen, 1996, 1997; Vimal, Pandey \& McCagg, 1995), and spectral/ color tuning (De Valois \& Jacobs, 1984; Engel, Zhang, \& Wandell, 1997). As per (Vimal, 2011a), "A psychophysical entity is an abstract mathematical construct derived by modeling the experimental data related to psychophysics and neurophysiology. For example, there are 3 psychophysical visual (cardinal (Krauskopf, Williams, \& Heeley, 1982)) channels (such as the Red-Green, the Yellow-Blue, and the achromatic or luminance channels) derived from psychophysical and physiological data (Hurvich \& Jameson, 1957; Kaiser \& Boynton 1996; Krauskopf, Williams, \& Heeley, 1982). [...] The genuine first-person measurements lead to the subjective experience of color qualia such as redness to greenness (see also (Dennett, 2003)). The third-person measurements will reveal the physical attributes such as neural activities in related neural-network that includes visual red-green (R-G) color area 'V4/V8/VO'. In addition, the experience of hue, saturation and brightness (first-person data) (Vimal et al, 1987) correlates with the activity of its neural-network and the properties of associated color stimuli (third-person data) (Bartels \& Zeki, 2000; Hadjikhani et al, 1998; Kaiser \& Boynton, 1996; Krauskopf et al, 1982; Tootell, Tsao, \& Vanduffel, 2003; Vimal, 1998b, 2002b; Wandell, 1999). This psychophysical entity (such as the R-G channel) provides a link between firstperson data (phenomenal or mental aspect, such as redness to greenness) and third-person data (physical aspect, such as 'V4/ V8/ VO R-G color neural-network'). Subjective experiences (SEs) redness to greenness and 'V4/ V8/ VO R-G color neural-network' are causally related via the Red-Green channel. That is, active 'V4/ V8/ VO R-G color neural-network' causes SEs redness 
to greenness upon the presentation of equiluminant red-green patterns via the spatial frequency (SF) tuned mechanisms of the Red-Green channel (Vimal, 1998b, 2002b); these are external stimulus driven SEs. Subjective experience of color can also occur by internal activation, such as electrical stimulation, transcranial magnetic stimulation (TMS), and 'meditation-induced cortical phosphenes with eyes closed' (Vimal \& Pandey-Vimal, 2007). [...] The color-contrast-constancy is partly achieved at high contrasts and the information processing at suprathreshold levels is different from that at the threshold levels (Vimal, 2000). Color and luminance SF discrimination thresholds have a different SF dependence; while color appears to perform better than luminance vision at low SFs, this effect is lost or even reversed at high SFs; color and form interact, but color and motion are largely segregated (i.e. they weakly interact) (Vimal, 2002a)."

\section{COLOR AS SUBJECTIVE VISUAL EXPERIENCE}

It is well-known that humans have three different types of cones in their eyes that perceive the blue, green, and red visible photons reflecting from objects. Human cones pigments have spectral peaks of about $445 \mathrm{~nm}, 535 \mathrm{~nm}$, and $570 \mathrm{~nm}$ (Hunt, Carvalho, Cowing, \& Davies, 2009). The color vision of $\mathrm{dogs}$ is dichromatic and they have only two types of light-catching cone photoreceptor pigments. These two types of pigments have spectral peaks of about 429 $\mathrm{nm}$ and $555 \mathrm{~nm}$ (Neitz, Geist, \& Jacobs, 1989). Dogs cannot see red, orange or green colors but red, orange and green appear as yellow or blue to them. Namely, dogs can see yellow, blue, and grey colors. Several types of birds have a fourth type of retinal cone photoreceptor cells (tetrachromatic UV (Ultraviolet), $300 \mathrm{~nm}$ ), so their vision is more refined as compared to human color vision.

When we can see a red apple at the same time, dogs can see this apple with yellow -like color. So the question can emerge, this apple in Figure 1 is red or yellow-like. A dog's subjective visual experience can be that this apple is yellow-like but a human's subjective visual experience is red. The correct definition could be that this apple under normal photopic circumstances for people with intact vision makes a red visual sense. So a color is not a physical feature of an given object but a subjective visual experience that is depend on the long wavelength sensitive (LWS or red) cone, middle wavelength sensitive (MWS or green) cone, and short wavelength sensitive (SWS or blue) cone/ photoreceptor and visual processes and also on the context of apple.

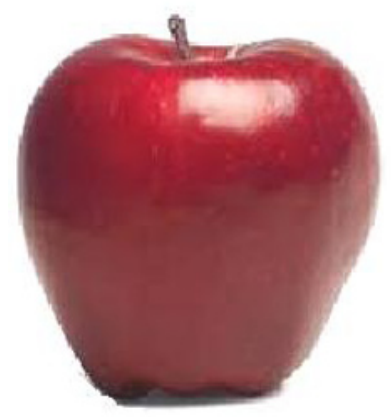

Figure 1. A red apple. When we can see a red apple at the same time, dogs can see this apple with yellow-like color. (See the related thoughts in the text.)

\section{ACHROMATIC AND CHROMATIC VISION}

Electromagnetic light waves (photons) visible to the human eye range from about 400 to 700 $\mathrm{nm}$. Attributes of visible photons/ light, such as wavelength and intensity, are physics; but 
color and its attributes (such as hue, saturation, and brightness (Vimal et al, 1987)) are subjective experiences, which are the mental aspect of color-related-neural-network-state (Vimal, 2008, 2010a, 2012). A hue is a pure color, i.e. one with no black or white in it. In our previous paper (Bókkon et al, 2011), we elaborated that the white light (visible electromagnetic photons) is a mixture of all colors. Black or white, it's not an all or nothing case in everyday life. White objects are white because the most of the light that falls on them is reflected by the material. Black objects absorb light of all frequencies but a little light (electromagnetic photons) is reflected from them. Thus, black is also a mixture of all colors! White and black have the same hue and saturation, and the lightness is all that is different. The sensation of black is not the same as absence of light is one of the central tenets of Hering's teaching (Hering, 1874).
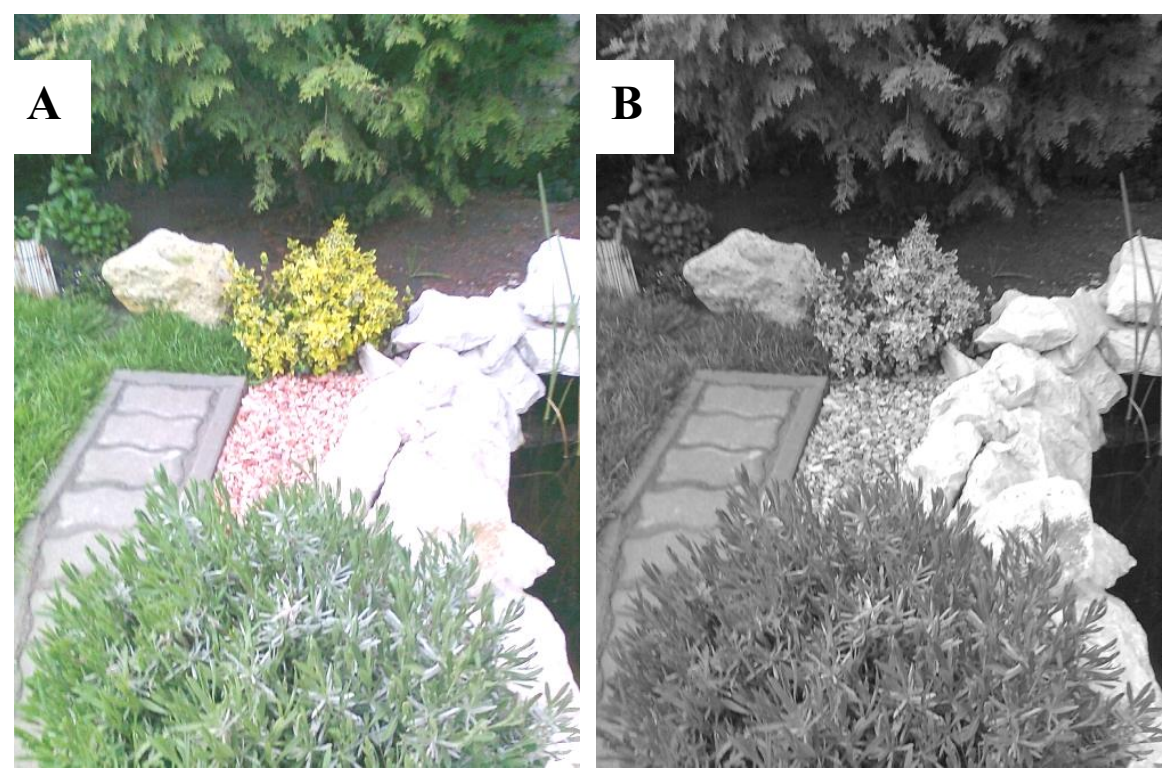

Figure 2. The same photo by colors (A) and by black (grey) and white (B).

When you can see the photo in Figure 2a under photopic level, you say that is a color photo that is your subjective experience (SE) about this photo due to the reflected mixture of visible "color" photons (mixture of electrom agnetic photons visible to the human eye range from about 400 to $700 \mathrm{~nm}$ wavelength).

When you can see the same photo in Figure $2 b$ under photopic level, you say that is a black and white photo. However, this is also your subjective experience about this photo but your blackness and whiteness subjective experiences about the photo of Figure $2 b$ are also due to the reflected mixture of visible "color" photons (mixture of electromagnetic photons visible to the human eye range from about 400 to $700 \mathrm{~nm}$ wavelength s).

In the human retina there are rods and three types of cones photoreceptors, each of which absorbs different range wavelengths (Figure 3) of external visible electromagnetic photons (Brown \& Wald, 1964). 


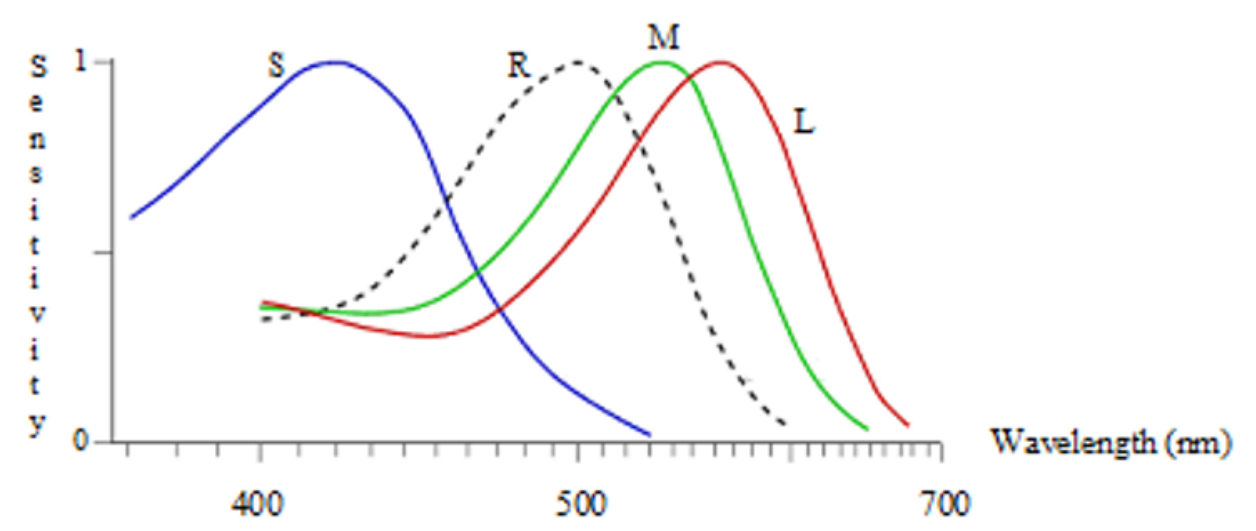

Figure 3. Photon absorption curve for R: rod is shown by black dotted curves., L: long wavelength sensitive cone by red curve, M: middle wavelength sensitive cone by green curve, and S: short wavelength sensitive cone by blue curve.

We can read essentially in the most of scientific literatures that rods do not discern colors like cones do (i.e., rod vision is achromatic night vision), although they are highly sensitive to light, and usually the photon absorption curve for rod is shown by black dotted curves., long wavelength sensitive cone by red curve, middle wavelength sensitive cone by green curve, and short wavelength sensitive cone by blue curve (see in Figure 3). However, rod photoreceptors convey electromagnetic visible photonic signals in the human eye ranging from about 400 to $700 \mathrm{~nm}$ wavelength; similarly for cones with limited range. Cones are for color vision, nevertheless, rods also absorb similar color photons as cones do, and they also could contribute to subjective color perception (Stabell \& Stabell, 1994; Cao, Pokorny, Smith, $\&$ Zele, 2008) to certain extent, but not like day color vision via 3 cones. In other words, but rods convey electromagnetic visible color mixed photonic signals in the human eye ranging from about 400 to $700 \mathrm{~nm}$ these produce subjective black and white experience in the brain. Although vision science makes practical difference between achromatic and chromatic vision, both are subjective experiences are produced by mixed visible color photon signals in the human eye ranging from about 400 to $700 \mathrm{~nm}$.

\section{MOD AL AND AMODAL VISUAL COMPLETION}

Although recent experiments provided evidence that visual, auditory, and somatosensory integrations take place parallel at numerous levels along brain pathways (Giard \& Peronnet, 1999; Macaluso, Frith, \& Driver, 2000; Calvert, Spence. \& Stein, 2004) and in our everyday perception most objects and events can be seen, heard, and touched, i.e. these are primarily intermodal perception, i.e. information from events or objects available to multiple senses simultaneously, for the understanding of our thoughts presented here we focus to visual perception per se.

A major challenge of vision research is to make it clear how the visual system can complete missing structures during visual perception. In our everyday awareness of the surrounding world in almost all cases of visual perception include one or more amodal parts. In amodal completion, there is a completion of an object that is not completely visible because it is covered (occluded, hidden) by something else (Kanizsa \& Gerbino, 1982). In modal completion phenomenon a shape can be perceived that is occluding other shapes even when the shape itself is not drawn (Figure 4). For example the triangle that appears to be occluding three disks in the Kanizsa triangle.

According to (Nanay, 2007), "amodal perception relies heavily on our background knowledge of how the occluded parts of the object (may) look. If I have never seen a cat, I will have difficulties attributing properties to its tail behind the fence". Nanay states that 
when we represent features of perceived objects that are not actually visible to us, we can use mental imagery. It is also true for visual imagery. If we want to visualize an object we must know how this look. In addition, our individual belief also can contribute to the representation of non-visible object features (Briscoe, 2011). Since during amodal completion as well as during modal visual completion we can experience such physical features of an object that are not due to the external visible photon signals absorbed by retinal photoreceptors, it supports that these processes are achieved by intrinsic mechanisms between V1 and higher level areas.

It seems that amodal visual completions are due to the visual perception induced visualization processes when our brain tries to interpret the unseen parts of objects or in modal visual completions the brain represent features of perceived objects that are not actually visible. These processes essentially depend on our background visual knowledge (and also our individual belief), namely, essentially depend on stored long-term (visual) memory. Thus we agree with Nanay that amodal visual perception can be a version of visualization, i.e. visualize the unseen parts of objects we are looking at.

Recent experiments by Murray et al. $(2002,2004)$ revealed that in humans both modal and amodal completion processes share a common initial neurophysiological spatiotemporal mechanism, but with differential processing latencies. It is possible that feedforward visual signals from V1 and V2 are sent to higher visual areas that modulate V1 and V2 responses to visual stimuli, which finally can produce modal completion or amodal completion (Albert, 2007; Murray et al., 2002, 2004). This modulation of V1 and V2 responses to external visual stimuli essentially depend on stored long-term visual memory (background visual knowledge). It is also possible that the completion of occluded contours (filling-in) phenomena are dependent on the spatial scale of the occlusion; local processing can account for small gaps or occlusions while larger gaps or occlusions most likely depend on feedback signals arising from neurons with significantly larger receptive fields.

One may argue that what allows us to see is the perception of surfaces and layout, these are amodal features, can be without color at all and can be achieved through suggesting edges or contours, as in the powerful demonstration of subjective contours, geometry/ form has very little to do with color per se, surface and edges are what show shape to the visual system.

Nevertheless, it is not true. As mentioned above, photoreceptors and various retinal cells process and convey essentially external visible electromagnetic (color) photonic information to LGN and to V1 and other visual areas that is modulated by additional sensory modalities during multisensory integration. It is possible that first steps of visual perception (and representation) are basically nothing other than representation of external visible (color) electromagnetic photons achieved in V1 CO-rich visual areas. During visual perception, information originated from surfaces and edges is also due to the external visible (color) electromagnetic photons.

During visual modal completion or amodal completion the first steps that detected external (color) photon signals are run from the retina via the LGN to V1, V2 and then signals conveyed to extrastriate and to higher level visual and association areas. Next, feedback signals (depends on our background visual knowledge originated from long term (visual) memory and also on our individual belief, Figure 5) modulate original detected and represented object in retinotopic V1, which finally makes modified perception, i.e. modal completion or amodal completion. This process is also consistent with the reverse hierarchy theory of vision. According to recent electroencephalogram (EEG) and functional magnetic resonance imaging (fMRI) experiments (Scholte, Jolij, Fahrenfort, \& Lamme, 2008), texture boundaries are detected in a feedforward manner and are represented at increasing latencies by higher visual regions. In addition, surface segregation is represented by reverse hierarchical processes that arise from feedback signals to early visual areas such as V1. 


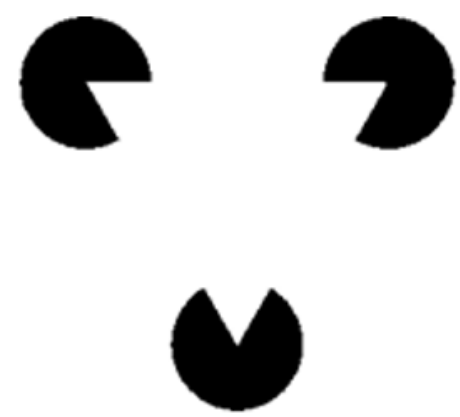

Figure 4. Modal visual completion. The triangle that appears to be occluding three disks in the Kanizsa triangle.
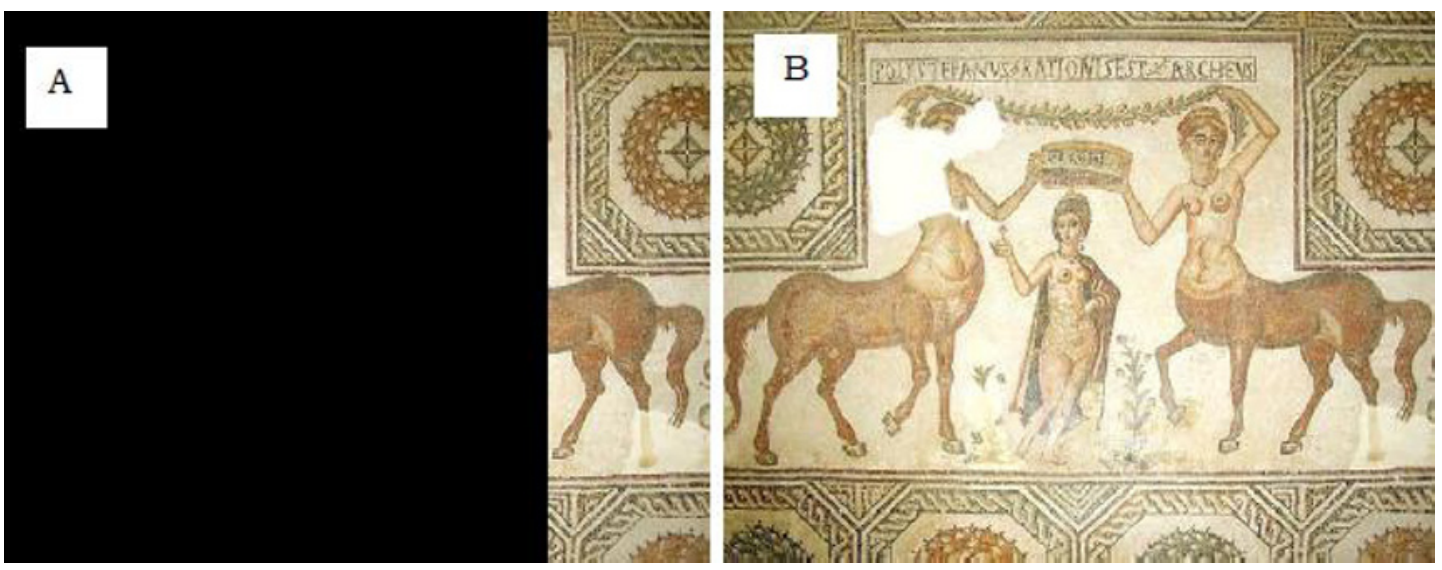

Figure 5. Amodal visual completion depends on our background visual knowledge and also on our individual belief. Our individual belief could suggest that partially covered unseen parts horse in A should be completed by our visual imagery to form an ordinary horse. But as B ind icates it is a female centaur. [Source: http:// en.wikipedia.org/ wiki/ File:GiorcesBardo55.jpg]

\section{SPATIAL VISUAL PERCEPTION AND IMAGERY}

Some researchers argue that visual and spatial imagery can be represented differently (Farah, Hammond, Levine, \& Calvanio, 1988; Vannucci and Mazzoni 2009). Nevertheless, according to their recent fMRI studies, Golomb and Kanwisher (2011) state, "despite our subjective impression that visual information is spatiotopic, even in higher level visual cortex, object location continues to be represented in retinotopic coordinates". In addition, they suggested that there is a not explicit hard-wired spatiotopic map in the brain and the spatiotopic object position can be computed not directly and continually reconstructed by each eye movement.

It is possible that our capacity for spatial visual perception and imagery are learned ability that performed/ computed by higher level visual and association areas (linked to other sensory modalities), but first steps of visual perception (and representation) is essentially nothing other than perception (and representation) of external visible electromagnetic photons achieved basically in retinotopic $\mathrm{V} 1$ mitochondrial-rich $\mathrm{CO}$ areas. 


\section{POSSIBLE ROLE OF BIOLUMINESCENT RETINAL BIOPHOTONS IN THE DEVELOPMENT OF RETINOGENICULATE PATHWAYS AND INITIAL APPEARANCE TOPOGRAPHIC MAP FORMATION OF V1 AND CO BLOBS BEFORE BIRTH}

Early visual experience is fundamental to shape the maturation of cortical circuits and is also indispensable to normal color and visual perception during development (Sugita, 2004). Experiments revealed that retinogeniculate pathways and $\mathrm{CO}$ blobs emerge before birth and visual experience is not essential for the initial appearance or early development of CO blobs in cats and macaques, which suggests that $\mathrm{CO}$ blobs could reflect an innate and structural organization of early visual cortex (Kuljis \& Rakic, 1990; Murphy, Duffy, Jones, \& Mitchell, 2001). Besides, the CO layout of the visual cortex is not modifiable by visual experiences (Murphy, Duffy, Jones, \& Mitchell, 2001).

It is generally believed that retinal waves play a major instructive role in the maturation of the visual system. During development of the visual system, in the higher and lower vertebrates, ganglion cells in the immature and light-insensitive retina spontaneously and synchronously creates endogenously waves (action potentials) that are transmitted to the lateral geniculate nucleus (Huberman, Feller, \& Chapman, 2008). Amacrine cells also participate in the correlated activity patterns. Spontaneous retinal waves are conveyed to the visual cortex and where can trigger endogenous spindle bursts.

Chalupa (2009) pointed out that retinal waves are doubtful to have such a role, and suggested that eye-specific molecular cues in combination with neuronal activity are probably involved in the development of eye-specific retinogeniculate pathways.

Nevertheless, several experiments proved (Kobayashi et al., 1999; Kataoka et al., 2001; Narici et al., 2009, 2012; Catalá, 2006; Adam, Kazakov, \& Kazakov, 2005; Nakano, 2005) that natural lipid peroxidation is one of the main sources of spontaneous ultraweak (bio)luminescent biophotons. Under regulated circumstances, lipid peroxidation is a natural process in cells and also in retinal membranes. Since the natural lipid peroxidation is one of the main sources of bioluminescent biophotons and the photoreceptors have the highest oxygen demand and polyunsaturated fatty acid (PUFA) concentration in the body (Nielsen, Maude, Hughes, 1986; Youdim, Martin, \& Joseph, 2000), there can be a permanent, low -level bioluminescent biophoton emission within the retina without any external light stimulation in the retinal of fetus in the uterus.

In addition, recently we (Wang, Bókkon, Dai \& Antal, 2011) presented the first experimental evidence of the existence of spontaneous and visible light induced (also called as delayed luminescence) ultraweak biophoton emission from in vitro freshly isolated rat's whole eye, lens, vitreous humor and retina. Our results support our previously predictions (Bókkon, 2008; Bókkon \& Vimal, 2009) that retinal discrete dark noise as well as retinal phosphenes can be due to the natural bioluminescent biophotons originated within the retinal system (Figure 6).

If we consider the above mentioned, it might suggest that continuously generated bioluminescent biophotons from retinal lipid peroxidation may also have functional role in early development of retinogeniculate pathways and initial appearance topographic organizations of $\mathrm{V} 1$ and $\mathrm{CO}$ blobs before birth, because retinal spontaneous biophotons can continuously send intrinsic signals via phototransduction cascade to the V1 area that interprets these retinal biophotons as if they originated in the external visual world. 


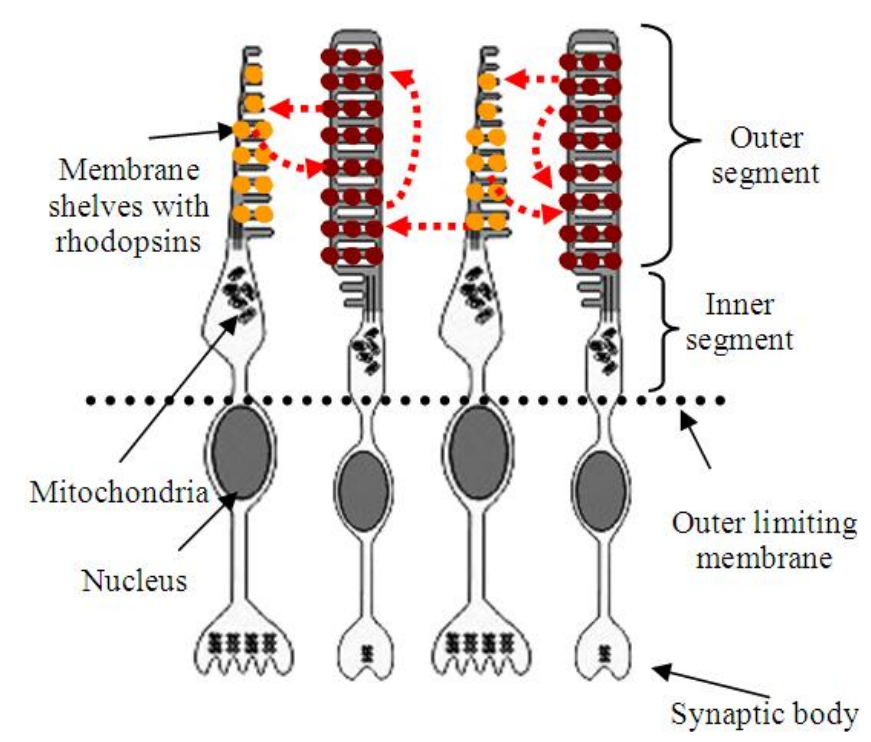

Figure 6. Bioluminescent biophotons from natural retinal lipid peroxidation indicated by red jagged arrows. It is possible that a given rod or cone emits a bioluminescent biophoton that changes its direction, and subsequently can absorb its own bioluminescent photon. A rod or cone can absorb bioluminescent biophotons from the lipid peroxidation of adjacent rods or cones.

\section{METAPHYSICS}

Since we are trying to explain subject experiences related to color (such redness), we must clearly disclose our metaphysics. (Vimal, 2012) discusses it as follows: One could categorize all entities of our universe in two categories ${ }^{1}$ : physical (P: such as fermions, bosons and their composites including classical inert entities and neural networks ( $\mathrm{NNs}$ ) in objective third person perspective (3pp)) and mental entities ( $M$ : such as subjective experiences, self, thoughts, attention, intention, and other non-physical entities in subjective first person perspective (1pp)). This categorization entails 4 major philosophical p ositions:

(i) $\mathrm{M}$ from $\mathrm{P}$ ( $\mathrm{P}$ is primitive/ fundamental; experiences emerge from the interactions of feed forward and feedback signals in neural-networks or identical with brain-states): naturalistic/physicalistic/materialistic nondual monism, physicalism, materialism, reductionism, non-reductive physicalism, naturalism, or Cārvāka/Lokāyata (800-500 BCE (BCE $=$ Before Common Era; $\mathrm{BC}=$ Before Christ; For example $400 \mathrm{BC}$ is $400 \mathrm{BCE})$ );

(ii) $\mathrm{P}$ from $\mathrm{M}$ ( $\mathrm{M}$ is primitive; matter-in-itself is 'congealed' mind): idealism, mentalistic nondual monism, or Advaita (788-820 AD (AD = Anno Domini, referring to the year of Christ's birth));(iii) $\mathrm{P}$ and $\mathrm{M}$ are independent but can interact when we are alive (both $\mathrm{P}$ and $\mathrm{M}$ are equally primitive: interactive substance dualism, Prakrti and Puruṣa of Sāmkhya (1000$600 \mathrm{BCE}$ or even before Gītā (3000 BCE) ${ }^{2}$; and (iv) P and M are two inseparable aspects of a state of an entity (fundamental entity, such as fermions and bosons, the 'primitive' quantum

\footnotetext{
${ }^{1}$ One could argue that categorizing the world into two categories, physical and mental, is the bases of psychophysics initiated by Fechner in the late 19th century and achieved the technical asymptote in Woodsworth and Schlosberg's Experimental Psychology text during the middle of the 20th century.

${ }^{2}$ The Gìta is a 700-verse scripture that is part of the Hindu epic Mahäbhārata. This scripture contains a conversation between Pāndava prince Arjuna and his guide Lord Krishna on a variety of theological and philosophical issues.
} 
field/ potential ${ }^{3}$ : dual-aspect monism, neutralism, Kashmir Shaivism (860-925 CE (CE = Common Era, recent term)) and Viśiștāadvaita (1017-1137 CE: mind (cit) and matter (acit) are adjectives of Brahman).

The subjective $1 \mathrm{pp}$-mental aspects of the states of entities were further investigated by Titchener (1867-1927) who proposed structuralism (influenced from Wundt's theory of voluntarism: 'will' is superior to intellect and emotion and is the basic factor both in the universe and in human conduct), where the structure of experience was studied by using subjective analytic introspection to disclose the building blocks of mental entities. He proposed three types of mental elements constituting conscious experience: Sensations (elements of perceptions: more than 44,000 different sensations), Images (elements of ideas), and affections (elements of emotions). These elements could be broken down into their respective attributes: quality, intensity, duration, clearness, and extent (Sheehy, 2003, pp.224226). The attribute 'quality' differentiates sensations; the 'intensity' and the 'duration' attributes refer to "the strength of an experience" and "the period an experience lasts", respectively; the 'clearness' attribute specifies "how much an experience stands out from its back ground" and the "extent' attribute refers to "experience in terms of spatial dimension" (Sheehy, 2003, p.227). Both sensations and images contain all of these qualities; however, affections lack in clearness and extensity/ extent; the id ea of associationism (the association of one mental state with its successor states for the operation of mental processes) entails how the mental elements combined and interacted with each other to form conscious experience; the law of contiguity (things that occur near each other in time or space are readily associated) implies that "the thought of something will tend to cause thoughts of things that are usually experienced along with it". ${ }^{4}$

The objective 3pp-physical aspects of the states of entities were further investigated by Boring (1886-1968) who attempted to accommodate behaviorism by viewing sensations through their 3pp-physical mechanisms from his monist physicalism perspective (Boring, \& Gardner, 1967); he focused on a physical brain rather than the abstract mind. This view may seem in direct opposition to mentalist and dualist perspective of his mentor Titchener, but it is complementary in our view because $3 \mathrm{pp}$-physcial and $1 \mathrm{pp}$-mental aspects of a state of brain is inseparable in our extended dual-aspect monism framework.

The framework (i)-materialism is the dominant view in science, and (ii)-idealism and (iii)interactive-substance-dualism are the dominant views in religions; all (i)-(iii) have serious problems. The framework (iv)-DAM has the least number of problems; the proposed DAMv framew ork is the extension/modification of DAM (DAM = Dual-Aspect Monism): As per (Vimal, 2011b), "The DAMv framework consists of three essential components: (1) the DualAspect Monism (Vimal, 2008), where each entity has inseparable mental and physical aspects; (2) dual-mode (Vimal, 2010a); and (3) varying degrees of the dominance of aspects depending on the levels of entities (Vimal, 2012)." As per (Vimal, 2012), "The mental aspect is from the subjective first person perspective and the physical aspect is from the objective third person perspective. This framework is optimal because it has the least number of problems (Vimal, 2010a)."

Dual aspect monism in this interpretation would mean that there is certain kind of reality that enables to produce mental experience and its correspond ing physical level. Critique can question: Is there something which presents advantage of this view for empirical sciences? Yes, there is indeed a great advantage on more realistic quantum physics based extended dual-aspect monism (DAMv) metaphysics compared to the obsolete classical physics based materialism. The DAMv framework (Vimal, 2008, 2010a, 2012) has the least number of problems compared to all other types of metaphysics (such as materialism, idealism, and interactive substance dualism). The problems are discussed in (Vimal, 2010b). Even neuroscientists Koch (2012) and Tononi (2004) have now changed their metaphysical view

\footnotetext{
${ }^{3}$ See ('t Hooft, 2005).p4 for 'primitive' quantum field, (Bohm, 1990) for quantum potential, and (Hiley \& Pylkkänen, 2005) for "primitive mind-like quality at the quantum level via active information".

${ }^{4}$ Adapted from <http://en.wikipedia.org/wiki/Structuralism_(psychology) >. See also (Titchener, 1929).
} 
from materialism to dual-aspect monism because this is closest to Fundamental Truth; this is summarized in (Vimal, 2012).

The dominant metaphysics of science is materialism, which has problems: As per (Vimal 2010b), "In [the identity theory of] materialism, a specific experience (SE: such as redness) is identical with a specific state (such as the redness-related state caused by long wavelength light) of a specific neural-network (such as red-green V4/ V8/ VO-neural-net) (Levin, 2006; Levin, 2008; Loar, 1990, 1997; Papineau, 2006). In [the emergence or reduction theory of materialism ...], qualia/ subjective experiences (such as redness) are assumed to mysteriously emerge or reduce to ... relevant states of neural-nets ... The major problem is Levine's explanatory gap (Levine, 1983): the gap between experiences and scientific descriptions of those experiences (Vimal, 2008). In other words, how can our experiences emerge (or arise) from non-experiential matter such as the neural-networks of our brain or organismenvironment interactions? [...] Furthermore, materialism/emergentism has 3 more assumptions (Skrbina, 2009): matter is the ultimate reality, and material reality is essentially objective and non-experiential. These assumptions need justification."

A specific SE is the realization of related potential SE. Potential SEs are superposed in the mental aspect of each entity-state in the DAMv framework (Vimal, 2008, 2010a, 2012). A specific SE is realized by (i) satisfying the necessary ingredients of consciousness (Vimal 2011a) elaborated later, and (ii) matching and selection mechanisms (Vimal, 2010a): (a) matching/ interaction of stimulus-dependent feed forward signals and cognitive feedback signals and (b) then selecting a specific SE related to stimulus from the virtual reservoir, which is the storage area for the potential SEs in superposed form in the mental aspect of each entity-state (elaborated later). An entity could be anything from quantum particle/ field to brain's neural-networks. A color stimulus is a reflected light (from about 400 to $700 \mathrm{~nm}$ wavelength) and/ or mixed visible photons of various wavelengths and intensities. These photons are absorbed in your photoreceptors and processed by retinal, LGN, and cortical neurons of various visual areas, specifically color-related V4/ V8/ VO-neural network (NN) elaborated below. A brain's NN-state has inseparable mental aspect (such as SE redness) and physical aspect (such as color-related V4/ V8/ VO-NN and its activities).

\section{CRITIQUES}

13.1. Critique 1: The manuscript is well articulated and would make an excellent contribution to the literature on philosophy of the mind. There are two minor issues. First, you have not shown that subjective visual experience must be excluded from materialism. Materialism is not simply the structure of the neural networks, but also the dynamics driven by the ionic composition and the electrical patterns that can manifest from the neural structure. Therefore, experience can emerge from non-experiential matter such as neural networks due to dynamic continuity. Second, you have not included selectionism (neural Darwinism) as a process of subjective experience. Finally throughout the manuscript there are numerous statements and assertions without supporting evidence. Therefore the manuscript should be revised so that assertions or hypothesis are supported by the literature; otherwise it should be made clear that such are not yet scientifically proven.

Reply: (1) Experiences cannot emerge from non-experiential matter by definition. An entity-state must have dual-aspect nature. The hypothesis of emergence is still mysterious but is addressed to some extent in (Vimal, 2010a) and (Vimal, 2012). The dynamics driven by the ionic composition and the electrical patterns that can manifest from the neural structure is discussed in (Vimal, 2010a). (2) The selectionism (neural Darwinism) as a process of subjective experience is discussed in (Vimal, 2010a) along with the matching and selection of specific experience. (3) The assertions or hypothesis are not supported by the literature are not yet scientifically proven. 


\section{SUMMARY}

Briefly summarized some important thoughts are shown below.

- $\quad$ The hypercolumn notion suggested by Hubel and Wiesel may be attractive, but to date, there are disagreements about the existence of hypercolumns.

- $\quad$ During visual perception and imagery, the high activity of cytochrome oxidase $(\mathrm{CO})$ is associated with high mitochond rial activity.

- $\quad$ The strict coupling between neuronal activity and oxidative energy metabolism is the basis for the use of $\mathrm{CO}$ as an endogenous metabolic marker for neurons.

- V1 contains local cluster of neurons jointly sensitive to orientation and color, perhaps corresponding to CO blobs.

- $\quad$ The highest density of neurons in neocortex (number of neurons per degree of visual angle) and the highest volume of gray matter of the retino-geniculostriate pathway devoted to representing the visual field are found in V1.

- It is probable that the visual attributes of color, form, and motion are not neatly segregated by V1 into different stripe compartments in V2.

- $\quad$ The CO blobs form nonlinear repeating functional units in V1.

- $\quad$ Feed-forward visual input from excited local circuits to V1 is necessary to phosphene aw areness.

- Attributes of visible photons/ light, such as wavelength and intensity, are physics; but color and its attributes such as hue, saturation, and brightness are subjective experiences.

Although vision science makes difference between achromatic and chromatic vision, both are subjective experiences are produced by mixed visible color photon signals in the human eye ranging from about 400 to $700 \mathrm{~nm}$.

- $\quad$ Reentrant processing between higher areas and early (V1) visual cortex is necessary for conscious and unconscious visual perception as well as for phosphene perception.

Here we argued that the visual perception and representation are essential based on perception and representation of colors (colors as external visible electromagnetic photon signals). This representation is the most energetic allocation procedure in the brain, which is logically achieved by highest density neuronal V1 regions with mitochondrial-rich CO blobs. Of course, perceived and represented colors (as visible electromagnetic photons) in V1 areas (and in CO blobs) are modulated by other sensory modalities during multisensory integration and are interpreted by superior level processes that finally produce subjective visual experiences.

It was suggested that the functional unit for phosphene induction can be linked to small clusters (3-4 blobs/ $\mathrm{mm}^{2}$ ) of CO blobs in V1 and not to the hypercolumns structures.

Although vision research makes difference between achromatic and chromatic vision, both are subjective color experiences produced by mixed visible (color) photon signals in the human eye ranging from about 400 to $700 \mathrm{~nm}$. In addition, we presented some thoughts related to the physics of visible photons/ light and its subjective experiences.

During visual modal completion or amodal completion the first steps that detected external (color) photon signals are run from the retina via the LGN to V1, V2 and then signals conveyed to extrastriate and to higher level visual and association areas. Then, feedback signals (depending on our background visual knowledge originated from long term (visual) memory and also on our individual belief) modulate original detected and represented object in retinotopic V1, which finally makes modified perception, i. e. modal completion or amodal completion. This process is also consistent with the reverse hierarchy theory of vision. 
Because bioluminescent biophotons can continuously send intrinsic signals to the V1 area that interprets these retinal biophotons as if they originated in the external visual world, we also raised that constantly produced biophotons from retinal lipid peroxidation might also have functional role in early development of retinogeniculate pathways as well as initial appearance topographic organizations of $\mathrm{V} 1$ and $\mathrm{CO}$ blobs before birth,

The link between structure (such as V4/ V8/VO-NN), function (such as detection and discrimination of color), and subjective experiences (such as redness and greenness) was explained best by the DAMv metaphysical framework because it has the least number of problems.

\section{DECLARATION OF IN TEREST}

The authors report no conflicts of interest. The authors alone are responsible for the content.

\section{ACKNOWLED GMENTS}

We would like to acknowledge Prof. Edward J. Tehovnik, Prof. Roman Richard Poznanski, and anonymous reviewers for helpful comments on the manuscript. Bókkon's URL: http:/ / bokkon-brainimagery.5mp.eu. The work was partly supported by VP-Research Foundation Trust and Vision Research Institute research fund to RLPV. Author would like to thank anonymous reviewers, ManjuUma C. Pandey-Vimal, Vivekanand Pandey Vimal, Shalini Pandey Vimal, and Love (Shyam) Pandey Vimal for their critical comments, suggestions, and grammatical corrections. RLPV is also affiliated with Dristi Anusandhana Sansthana, A-60 Umed Park, Sola Road, Ahmedabad-61, Gujrat, India; Dristi Anusandhana Sansthana, c/ o NiceTech Computer Education Institute, Pendra, Bilaspur, C.G. 495119, India; and Dristi Anusandhana Sansthana, Sai Niwas, East of Hanuman Mandir, Betiahata, Gorakhpur, U.P. 273001, India. Corresponding author's Email: bokkoni@yahoo.com. RLPV's email addresses are rlpvimal@yahoo.co.in and rlpvimal@gmail.com; URL: http:/ / sites.google.com/site/ rlpvimal/ Home/ .

\section{REFEREN CES}

t Hooft, G. ed. (2005). Fifty years of Yang-Mills theory. World Scientific Publishing Co. Pte. Ltd., Singapore.

Adam, W., Kazakov, D.V., \& Kazakov, V.P. (2005). Singlet-oxygen chemiluminescence in peroxide reactions. Chemical Reviews. 105, 3371-87.

Adams, D.L., Sincich, L.C., \& Horton, J.C. (2007). Complete pattern of ocular dominance columns in human primary visual cortex. Journal of Neuroscience. 27, 10391-403.

Ahissar, M., \& Hochstein, S. (1997). Task difficulty and the specificity of perceptual learning. Nature. $387,401-6$.

Albert, M.K. (2007). Mechanisms of modal and amodal interpolation. Psychological Review. 114, 455-69.

Bartels, A., \& Zeki, S. (1998). The theory of multistage integration in the visual brain. Proceeding. Biological Sciences / The Royal Society. 265, 2327-32.

Bartels, A., \& Zeki, S. (2000). The architecture of the colour centre in the human visual brain: new results and a review. European Journal of Neuroscience. 12, 172-93.

Basole, A., Kreft-Kerekes, V., White, L.E., \& Fitzpatrick, D. (2006). Cortical cartography revisited: A frequency perspective on the functional architecture of visual cortex. Progress in Brain Research. 154:121-34.

Basole, A., White, L.E., \& Fitzpatrick, D. (2003). Mapping multiple features in the population response of visual cortex. Nature. 423, 986-90.

Bohm, D. (1990). A new theory of the relationship of mind and matter. Philosophical Psychology. 3, 27186.

Bókkon, I. (2008). Phosphene phenomenon: a new concept. BioSystems. 92, 168-74.

Bókkon, I., \& Vimal, R.L.P. (2009). Retinal phosphenes and discrete dark noises in rods: a new biophysical framew ork. Journal of Photochemistry and Photobiology B: Biology. 96, 255-9.

Bókkon, I., \& Vimal, R.L.P. (2010). Implications on visual apperception: energy, duration, structure and synchronization. BioSystems. 101, 1-9. 
Bókkon, I., Vimal, R.L.P., Wang, C., Dai, J., Salari, V., Grass, F., \& Antal, I. (2011). Visible light induced ocular delayed bioluminescence as a possible origin of negative afterimage. Journal of photochemistry and photobiology. B, Biology. 103, 192-9.

Boring, E.G., \& Gardner, L. eds. (1967). A history of psychology in autobiography. The Century Psychology Series. 5, 449-75. Connecticut: Appleton-Century-Crofts.

Borst, G., \& Kosslyn, S.M. (2008). Visual mental imagery and visual perception: structural equivalence revealed by scanning processes. Memory \& Cognition. 36, 849-62.

Boyer, J.L., \& Harrison, S., Ro, T. (2005). Unconscious processing of orientation and color without primary visual cortex. Proceedings of the National Academy of Sciences of the United States of America. 102, 16875-9.

Brindley, G.S., \& Lewin, W.S. (1968). The sensations produced by electrical stimulation of the visual cortex. Journal of Physiology. 196, 479-93.

Briscoe, R.E. (2011). Mental Imagery and the Varieties of Amodal Perception. Pacific Philosophical Quarterly. 92, 153-73.

Brown, P.K., \& Wald, G. (1964). Visual Pigments in Single Rods and Cones of the Human Retina. Science. $144,45-52$.

Bruzzo, A.A., \& Vimal, R.L.P. (2007). Self: An adaptive pressure arising from self-organization, chaotic dynamics, and neural Darwinism. Journal of Integrative Neuroscience. 6, 541-66.

Calvert, G.A., Spence. C., \& Stein. E.B. (2004). The Handbook of Multisensory Processes. MIT Press, Cambridge.

Cao, D., Pokorny, J., Smith, V.C., \& Zele, A.J. (2008). Rod contributions to color perception: linear with rod contrast. Vision Research. 48, 2586-92.

Carder, R.K. (1997). Immunocytochemical characterization of AMPA-selective glutamate receptor subunits: laminar and compartmental distribution in macaque striate cortex. Journal of Neuroscience. $17,3352-63$.

Carder, R.K., \& Hendry, S.H. (1994). Neuronal characterization, compartmental distribution, and activity-dependent regulation of glutamate immunoreactivity in adult monkey striate cortex. Journal of Neuroscience. 14, 242-62.

Catalá, A. (2006). An overview of lipid peroxidation with emphasis in outer segments of photoreceptors and the chemiluminescence assay. International Journal of Biochemistry \& Cell Biology. 38, 1482-95.

Cattaneo, Z., Bona, S., \& Silvanto, J. (2012). Cross-adaptation combined with TMS reveals a functional overlap between vision and imagery in the early visual cortex. NeuroImage. 59, 3015-20.

Cavusoglu, M., Bartels, A., Yesilyurt, B., Uludağ, K. (2012). Retinotopic maps and hemodynamic delays in the human visual cortex measured using arterial spin labeling. Neuroimage. 59, 4044-54.

Chalupa, L,M. (2009). Retinal waves are unlikely to instruct the formation of eye-specific retinogeniculate projections. Neural Development. 4, 25.

Chen, W,. Kato, T., Zhu, X.H., Ogawa, S., Tank, D.W., \& Ugurbil, K. (1998). Human primary visual cortex and lateral geniculate nucleus activation during visual imagery. Neuroreport. 9, 3669-74.

Cichy, R.M., Heinzle, J., \& Haynes, J.D. (2012). Imagery and perception share cortical representations of content and location. Cerebral Cortex. 22, 372-80.

Cowey, A., \& Walsh, V. (2000). Magnetically induced phosphenes in sighted, blind and blindsighted observers. Neuroreport. 11, 3269-73.

De Valois, R.L., \& Jacobs, G.H. (1984). Neural mechanisms of color vision (Chapter 10). In Darian-Smith I. ed. Handbook of physiology: The Nervous System. Williams and Wilkins, Baltimore, 425-45.

Dennett, D.C. (2003). Who's on first? Heterophenomenology explained. Journal of Consciousness Studies. $10,10-30$.

Economides, J.R., Sincich, L.C., Adams, D.L., \& Horton, J.C. (2011). Orientation tuning of cytochrome oxidase patches in macaque primary visual cortex. Nature Neuroscience. 14, 1574-80.

Engel, S., Zhang, X., \& Wandell, B. (1997). Colour tuning in human visual cortex measured with functional magnetic resonance imaging. Nature. 388, 68-71.

Farah, M.J., Hammond, K.M., Levine, D.N., \& Calvanio, R. (1988). Visual and spatial mental imagery: dissociable systems of representation. Cognitive Psychology. 20, 439-62.

Fendrich, R., Wessinger, C.M., \& Gazzaniga, M.S. (1992). Residual vision in a scotoma: implications for blind sight. Science. 258, 1489-91.

Ffytche, D.H., \& Zeki, S. (2011). The primary visual cortex, and feedback to it, are not necessary for conscious vision. Brain. 134(Pt 1):247-57.

Fried, P.J., Elkin-Frankston, S., Rushmore, R.J., Hilgetag, C.C., \& Valero-Cabre, A. (2011). Characterization of visual percepts evoked by noninvasive stimulation of the human posterior parietal cortex. PLoS One. 6, e27204. 
Ganis, G., Thompson, W.L., Mast, F.W., \& Kosslyn, S.M. (2003). Visual imagery in cerebral visual dysfunction. Neurologic Clinics. 21, 631-46.

Giard, M.H., \& Peronnet, F. (1999). Auditory-visual integration during multimodal object recognition in humans: a behavioral and electrophysiological study. Journal of Cognitive Neuroscience. 11, 473-90.

Girard, P., Hupé, J.M., \& Bullier, J. (2001). Feed forw ard and feedback connections between areas V1 and V2 of the monkey have similar rapid conduction velocities. Journal of Neurophysiology. 85, 1328-31.

Golomb, J.D., \& Kanwisher, N. (2011). Higher Level Visual Cortex Represents Retinotopic, Not Spatiotopic, Object Location. Cerebral Cortex. 22, 2794-810.

Hadjikhani, N., Liu, A.K., Dale, A.M., Cavanagh, P., \& Tootell, R.B. (1998). Retinotopy and color sensitivity in human visual cortical area V8. Nature Neuroscience. 1, 235-24.

Hering, E. (1874). Zur Lehre vom Lichtsinn. IV. U“ ber die sogenannte Intensita" t der Lichtemp findung und $u$ " ber die Empfindung des Schwarzen. Sitzungsberichte der Kaiserlichen Akademie der Wissenschaften in Wien. Mathematisch-naturw issenschaftliche Classe. Abth. III 69, 85-104.

Hiley, B.J., \& Pylkkänen, P. (2005). Can Mind Affect Matter Via Active Information? Mind and Matter. 3, $7-27$.

Hochstein, S., \& Ahissar, M. (2002). View from the top: hierarchies and reverse hierarchies in the visual system. Neuron. 36, 791-804.

Hochstein, S., Barlasov, A., Hershler, O., Nitzan, A., \& Shneor, S. (2004). Rapid vision is holistic. Journal of Vision. 4, 95.

Horton, J.C., \& Adams, D.L. (2005). The cortical column: a structure without a function. Philosophical Transactions of the Royal Society of London. Series B, Biological Sciences. 360, 837-62.

Hubel, D.H., \& Wiesel, T.N. (1962). Receptive fields, binocular interaction and functional architecture in the cat's visual cortex. Journal of Physiology. (Lond) 160, 106-154.

Hubel, D.H., \& Wiesel, T.N. (1974). Sequence regularity and geometry of orientation columns in the monkey striate cortex. Journal of Comparative Neurology. 158, 267-94.

Hubel, D.H., \& Wiesel, T.N. (1977). Functional architecture of macaque monkey visual cortex. Proceedings of the Royal Society B: Biological Sciences.198, 1-59.

Huberman, A.D., Feller, M.B., \& Chapman, B. (2008). Mechanisms Underlying Development of Visual Maps and Receptive Fields. Annual Review of Neuroscience. 31, 479-50.

Hunt, D.M., Carvalho, L.S., Cowing, J.A., \& Davies, W.L. (2009). Evolution and spectral tuning of visual pigments in birds and mammals. Philosophical Transactions of the Royal Society of London. Series B, Biological Sciences. 364, 2941-55.

Hurvich, L.M., \& Jameson, D. (1957). An opponent-process theory of color vision. Psychological Review. 64, Part 1(6), 384-404.

Kaiser, P.K., \& Boynton, R.M. (1996). Human Color Vision. (2nd ed.), Optical Society of America, Washington, D.C.

Kammer, T. (1999). Phosphenes and transient scotomas induced by magnetic stimulation of the occipital lobe: their topographic relationship. Neuropsychologia. 37, 191-8.

Kanizsa, G., \& Gerbino, W. (1982). “A modal completion: Seeing or thinking?” In Beck J, ed. Organisationand Representation in Perception. Law rence Erlbaum Associates, Hillsdale, New Jersey.

Kataoka, Y., Cui Y., Yamagata, A., Niigaki, M., Hirohata, T., Oishi, N., \& Watanabe, Y. (2001). Activity dependent neural tissue oxidation emits intrinsic ultraweak Photons. Biochemical and Biophysical Research Communications. 285, 1007-11.

Kennedy, H., Dehay, C., \& Horsburgh, G. (1990). Striate cortex periodicity. Nature. 348, 494.

Klein, I., Dubois, J., Mangin, J.F., Kherif, F., Flandin, G., Poline, J.B., Denis, M., Kosslyn, S.M., \& Le Bihan, D. (2004). Retinotopic organization of visual mental images as revealed by functional magnetic resonance imaging. Brain Research. Cognitive Brain Research. 22, $26-31$.

Kobayashi, M., Takeda, M., Sato, T., Yamazaki, Y., Kaneko, K., Ito, K., Kato, H., \& Inaba, H. (1999). In vivo imaging of spontaneous ultraweak photon emission from a rat's brain correlated with cerebral energy metabolism and oxid ative stress. Neuroscience Research. 34, 103-13.

Koch, C. (2012). Consciousness: Confessions of a Romantic Reductionist. MIT Press, Cambridge.

Koivisto, M., \& Silvanto, J. (2012). Visual feature binding: the critical time windows of V1/ V2 and parietal activity. Neuroimage. 59, 1608-14.

Koivisto, M., Mäntylä, T., \& Silvanto, J. (2010). The role of early visual cortex (V1/ V2) in conscious and unconscious visual perception. Neuroimage. 51, 828-34.

Kosslyn, S.M. (1994). Image and brain: The resolution of the imagery debate. MIT Press, Cambrid ge.

Krauskopf, J., Williams, D.R., \& Heeley, D.W. (1982). Cardinal directions of color space. Vision Research. $22,1123-31$. 
Kuljis, R.O., \& Rakic, P. (1990). Hypercolumns in primate visual cortex can develop in the absence of cues from photoreceptors. Proceedings of the National Academy of Sciences of the United States of America. 87, 5303-6.

Levin, J. (2006). What is a Phenomenal Concept? In Alter T, Walter S. eds. Phenomenal Concepts and Phenomenal Knowledge New essays on Consciousness and Physicalism. Oxford University Press, Oxford, $87-110$.

Levin, J. (2008). Taking Type-B Materialism Seriously. Mind \& Language. 23, 402-25.

Levine, J. (1983). Materialism and qualia: The explanatory gap. Pacific Philosophical Quarterly. 64, 354-61.

Loar, B. (1990). Phenomenal states. Philosophical Perspectives. 4, 81-108.

Loar, B. (1997). Phenomenal states. Revised edition. In Block N, Flanagan O, Güzeldere G. eds. The Nature of Consciousness. MIT Press, Cambridge.

Lu, H.D., \& Roe, A.W. (2008). Functional organization of color domains in V1 and V2 of macaque monkey revealed by optical imaging. Cerebral Cortex. 18, 516-33.

Lund, J.S., Angelucci, A., \& Bressloff, P.C. (2003). Anatomical substrates for functional columns in macaque monkey primary visual cortex. Cerebral Cortex. 13, 15-24.

Macaluso, E., Frith, C.D., \& Driver, J. (2000). Modulation of human visual cortex by crossmodal spatial attention. Science. 289, 1206-8.

Marg, E., \& Rudiak, D. (1994). Phosphenes induced by magnetic stimulation over the occipital brain: description and probable site of stimulation. Optometry and Vision Science. 71, 301-11.

Merabet, L.B., Theoret, H., \& Pascual-Leone, A. (2003). Transcranial magnetic stimulation as an investigative tool in the study of visual function. Optometry and Vision Science. 80, 356-68.

Metha, A.B., \& Mullen, K.T. (1996). Temporal mechanisms underlying flicker detection and identification for red-green and achromatic stimuli. Journal of the Optical Society of A merica A: Optics, Image Science, and Vision. 13, 1969-80.

Metha, A.B., \& Mullen, K.T. (1997). Red-Green and achromatic temporal filters: a ratio model predicts contrast-dependent speed perception. Journal of the Optical Society of A merica A: Optics, Image Science, and Vision. 14, 984-96.

Mountcastle, V.B. (1957). Modality and topographic properties of single neurons of cat's somatic sensory cortex. Journal of Neurophysiology. 20, 408-34.

Murphy, K.M., Duffy, K.R., Jones, D.G., \& Mitchell, D.E. (2001). Development of cytochrome oxidase blobs in visual cortex of normal and visually deprived cats. Cerebral Cortex. 11, 122-35.

Murphy, K.M., Jones, D.G., Fenstemaker, S.B., Pegado, V.D., Kiorpes, L., \& Movshon, J.A. (1998). Spacing of cytochrome oxidase blobs in visual cortex of normal and strabismic monkeys. Cerebral Cortex. 8, 237-44.

Murray, M.M., Foxe, D.M., Javitt, D.C., \& Foxe, J.J. (2004). Setting boundaries: brain dynamics of modal and amodal illusory shape completion in humans. Journal of Neuroscience. 24, 6898-903.

Murray, M.M., Wylie, G.R., Higgins, B.A., Javitt, D.C., Schroeder, C.E., \& Foxe, J.J. (2002). The spatiotemporal dynamics of illusory contour processing: combined high-density electrical mapping, source analysis, and functional magnetic resonance imaging. Journal of Neuroscience. 22, 5055-73.

Nakagama, H., \& Tanaka, S. (2004). Self-organization model of cytochrome oxidase blobs and ocular dominance columns in the primary visual cortex. Cerebral Cortex. 14, 376-86.

Nakano, M. (2005). Low-level chemiluminescence during lipid peroxidations and enzymatic reactions. Journal of Bioluminescence and Chemiluminescence. 4, 231-40.

Nanay, B. (2007). Four theories of amodal perception. In McNamara DS, Trafton JG. eds. Proceedings of the 29th Annual Conference of the Cognitive Science Society (CogSci 2007). Hillsdale, NJ: Lawrence Erlbaum, 2007, pp. 1331-6. http:/ / csjarchive.cogsci.rpi.edu/ proceedings/ 2007/ docs/p 1331.pdf

Narici, L., De Martino, A., Brunetti, V., Rinaldi, A., Sannita, W.G., \& Paci, M. (2009). Radicals excess in the retina: A model for light flashes in space. Radiation Measurements. 44, $203-5$.

Narici, L., Paci, M., Brunetti, V., Rinaldi, A., Sannita, W.G., \& De Martino, A. (2012). Bovine rod rhodopsin. 1. Bleaching by luminescence in vitro by recombination of radicals from polyunsaturated fatty acids. Free Radical Biology \&Medicine. 53, 482-7.

Neitz, J., Geist, T., \& Jacobs, G.H. (1989). Color vision in the dog. Visual neuroscience. 3, 119-25.

Nielsen, J.C., Maude, M.B., Hughes, H. (1986). Anderson R.E. Rabbit photoreceptor outer segments contain high levels of docosapentaenoic acid. Investigative Ophthalmology \& Visual Science. 27, 261-4.

O'Kusky, J., \& Colonnier, M. (1982). A laminar analysis of the number of neurons, glia, and synapses in the visual cortex (area 17) of adult macaque monkeys. Journal of Comparative Neurololy. 210, 278-90.

Papineau, D. (2006). Phenomenal and Perceptual Concepts. In Alter T, Walter S. eds. Phenomenal Concepts and Phenomenal Knowledge New Essays on Consciousness and Physicalism. Oxford University Press, Oxford, 111-44. 
Pereira Jr A. (2012). Triple-Aspect Monism: A conceptual framework for the science of human consciousness. In Pereira Jr, Lehmann D. eds. The Unity of Brain, Mind and World: Current perspectives on a science of consciousness. Cambridge University Press, Cambridge, Forthcoming.

Powell, T.P.S., \& Mouncastle, V.B. (1959). Some aspects of the functional organisation of the postcentral gyrus of the monkey: a correlation of findings obtained in a single unit analysis with cytoarchitecture. Bulletin of the Johns Hopkins Hospital. 105, 133-62.

Preuss, T.M., \& Kaas, J.H. (1996). Cytochrome oxidase 'blobs' and other characteristics of primary visual cortex in a lemuroid primate, Cheirogaleus medius. Brain, Behavior and Evolution. 47, 103-12.

Ptito, A., \& Leh, S.E. (2007). Neural substrates of blindsight after hemispherectomy. Neuroscientist. 13, 506-18.

Rockel, A.J., Hoirns, R.W., \& Powell, T.P.S. (1980). The basic uniformity of structure of the neocortex. Brain. 103, 221-44.

Rockland, K.S. (1997). Elements of cortical architecture: hierarchy revisited. In Rockland KS, Kaas JH, Peters A. eds. Cerebral cortex: Extrastriate cortex in primates. Plenum Press, New York.

Salminen-Vaparanta, N., Koivisto, M., Noreika, V., Vanni, S., \& Revonsuo, A. (2012). Neuronavigated transcranial magnetic stimulation suggests that area V2 is necessary for visual awareness. Neuropsychologia. 50, 1621-7.

Scholte, H.S., Jolij, J., Fahrenfort, J.J., \& Lamme, V.A. (2008). Feed forw ard and recurrent processing in scene segmentation: electroencephalography and functional magnetic resonance imaging. Journal of Cognitive Neuroscience. 20, 2097-109.

Sheehy, N. (2003). Fifty Key Thinkers in Psychology. New York: Routledge http:/ / www.drbrem.net/ CPY679/ tichenerbio.pdf

Silvanto, J., Cowey, A., Lavie, N., \& Walsh, V. (2005). Striate cortex (V1) activity gates awareness of motion. Nature Neuroscience. 8, 143-4.

Sincich, L.C., \& Horton, J.C. (2005). The circuitry of V1 and V2: integration of color, form, and motion. Annual Review of Neuroscience. 28, 303-26.

Sincich, L.C., Jocson, C.M., \& Horton, J.C. (2007). Neurons in V1 patch columns project to V2 thin stripes. Cerebral Cortex. 17, 935-41.

Skrbina, D. (2009). Minds, objects, and relations: Toward a dual-aspect ontology (Chapter 19). In Skrbina D. ed. Mind that abides: Panpsychism in the new millennium. John Benjamins, Amsterdam, 36182.

Sparing, R., Mottaghy, F.M., Ganis, G., Thompson, W.L., Töpper, R., Kosslyn, S.M., \& Pascual-Leone, A. (2002). Visual cortex excitability increases during visual mental imagery--a TMS study in healthy human subjects. Brain Research. 938, 92-7.

Stabell, U., \& Stabell, B. (1994). Mechanisms of chromatic rod vision in scotopic illumination. Vision Research. 34, 1019-27.

Sugita, Y. (2004). Experience in early infancy is indispensable for color perception. Current Biology. 14, $1267-71$.

Takahata, T., Higo, N., Kaas, J.H., Yamamori, T. (2009). Expression of immediate-early genes reveals functional compartments within ocular dominance columns after brief monocular inactivation. Proceedings of the National A cademy of Sciences of the United States of America. 106, 12151-5.

Taylor, P.C., Walsh, V., \& Eimer, M. (2010). The neural signature of phosphene perception. Human Brain Mapping. 31, 1408-17.

Tehovnik, E.J., \& Slocum, W.M. (2007). What delay fields tell us about striate cortex. Journal of Neurophysiology. 98, 559-76.

Titchener, E.B. (1929). Systematic Psychology: Progelomena. New York, The Macmillen Company.

Tononi, G. (2004). An information integration theory of consciousness. BMC Neuroscience. 5, 42.

Tootell, R.B.H., Tsao, D., \& Vanduffel, W. (2003). Neuroimaging weighs in: humans meet macaques in "primate" visual cortex. Journal of Neuroscience. 23, 3981-9.

Treisman, A. (1996). The binding problem. Current Opinion in Neurobiology. 6, 171-8.

Vannucci, M., \& Mazzoni, G. (2009). Individual differences in object and spatialimagery: Personality correlates. Personality and Individual Differences. 46, 402-5.

Vimal, R.L.P. (1997). Orientation tuning of the spatial-frequency-tuned mechanisms of the Red-Green channel. Journal of the Optical Society of A merica A: Optics, Image Science, and Vision. 14, 2622-32.

Vimal, R.L.P. (1998a). Color-luminance interaction: data produced by oblique cross masking. Journal of the Optical Society of A merica A: Optics, Image Science, and Vision. 15, 1756-66.

Vimal, R.L.P. (1998b). Spatial-frequency tuning of sustained nonoriented units of the Red-Green channel. Journal of the Optical Society of A merica A: Optics, Image Science, and Vision. 15, 1-15.

Vimal, R.L.P. (2000). Spatial color contrast matching: broad-bandpass functions and the flattening effect. Vision Research. 40, 3231-43. 
Vimal, R.L.P. (2002a). Spatial frequency discrimination: a comparison of achromatic and chromatic conditions. Vision Research. 42, 599-611.

Vimal, R.L.P. (2002b). Spatial frequency tuned mechanisms of the Red-Green channel estimated by oblique masking. Journal of the Optical Society of A merica A: Optics, Image Science, and Vision. 19, 27688.

Vimal, R.L.P. (2008). Proto-experiences and Subjective Experiences: Classical and Quantum Concepts. Journal of Integrative Neuroscience. 7, 49-73.

Vimal, R.L.P. (2010a). Matching and selection of a specific subjective experience: conjugate matching and subjective experience. Journal of Integrative Neuroscience. 9, 193-251.

Vimal, R.L.P. (2010b). On the Quest of Defining Consciousness. Mind and Matter. 8, 93-121.

Vimal, R.L.P. (2011a). Necessary ingredients of consciousness: integration of psychophysical, neurophysiological, and consciousness research for the red-green channel. Vision Research Institute: Living Vision and Consciousness Research 2, 1-50. (accessed May 11, 2012).

URL<http:/ / sites.google.com/ site/ rlpvimal/ Home/ 2009-Vimal-Necessary-Ingred ientsConciousness-LVCR-2-1.pdf $>$

Vimal, R.L.P. (2011b). Scientific religions: science-religion unification through extended dual-aspect monism and its novel critiques. Vision Research Institute: Living Vision and Consciousness Research 4(8): $1-50$.

URL $<$ http:/ / sites.google.com/ site/ rlpvimal/ Home/ 2011-Vimal-Problems-Dualism-ReligionsDAM-4-8.pdf $>$ (accessed May 11, 2012).

Vimal, R.L.P. (2012). Emergence in dual-aspect monism. In Pereira JrA, Lehmann D. eds. The Unity of Mind, Brain and World: Current Perspectives on a Science of Consciousness. Cambridge University Press, Cambridge, In preparation [Available for comments:

$<$ http:/ / sites.google.com/ site/ rlpvimal/ Home/ 2012-Vimal-Emergence-UMBW-CUP-2.doc>], forthcoming.

Vimal, R.L.P., \& Pandey-Vimal, M-UC. (2007). Ancient historical scripture and color vision. Color Research \& Application. 32, 332-3.

Vimal, R.L.P., Pandey, R., \& McCagg, A.C. (1995). Temporal color contrast matching: the flattening effect and color-contrast-constancy. Investigative Ophthalmology \& Visual Science. 36, 664 (abstract).

Vimal, R.L.P., Pokorny, J.M., \& Smith, V.C. (1987). Appearance of steadily viewed light. Vision Research. 27, 1309-18.

Wandell, B.A. (1999). Computational neuroimaging of human visual cortex. Annual Review of Neuroscience. 22, 145-173.

Wang, C., Bókkon, I., Dai, J., \& Antal, I. (2011). First experimental demonstration of spontaneous and visible light-induced photon emission from rat eyes. Brain Research. 1369, 1-9.

Wikler, K.C., \& Rakic, P. (1990). Distribution of photoreceptor subtypes in the retina of diurnal and nocturnal primates. Journal of Neuroscience. 10, 3390-401.

Wong-Riley, M., Anderson, B., Liebl, W., \& Huang, Z. (1998). Neurochemical organization of the macaque striate cortex: correlation of cytochrome oxidase with Na+K+ATPase, NADPH-diaphorase, nitric oxide synthase, and N-methyl-D-aspartate receptor subunit 1. Neuroscience. 83, 1025-45.

Wong-Riley, M.T. (1989). Cytochrome oxidase: an endogenous metabolic marker for neuronal activity. Trends in Neurosciences. 12, 94-101.

Xiao, Y., \& Felleman, D.J. (2004). Projections from primary visual cortex to cytochrome oxidase thin stripes and interstripes of macaque visual area 2. Proceedings of the National Academy of Sciences of the United States of America. 101, 7147-51.

Youdim, K.A., Martin, A., \& Joseph, J.A. (2000). Essential fatty acids and the brain: possible health implications. International Journal of Developmental Neuroscience. 18, 383-99.

Zeki, S.M. (1977). Simultaneous anatomical demonstration of the representation of the vertical and horizontal meridians in areas V2 and V3 of rhesus monkey visual cortex. Proceedings of the Royal Society of London. Series B, Biological sciences. 195, 517-23. 